\title{
Aplicação de Polissacarídeos como Fase Estacionária em Análise Cromatográfica de Cátions
}

\author{
Roberta Signini, Ellen C. G. Moura, Maria G. O. Tavares \& \\ Guilherme R. Oliveira
}

O aproveitamento da biomassa vegetal é importante para o desenvolvimento das diversas áreas da ciência e tecnologia. Dentre os componentes macromoleculares importantes da biomassa vegetal estão a celulose e a quitina, sendo que o tratamento químico do segundo polissacarídeo leva a produção da quitosana. Neste trabalho, a celulose e a celulose impregnada com quitosana foram utilizadas como suporte cromatográfico para a separação de cátions metálicos, cobre, zinco, ferro e chumbo. A impregnação das placas cromatográficas com quitosana melhorou a separação e a resolução das análises e, paralelamente, observou-se que a maior a concentração de quitosana nas camadas de celulose aumenta a retenção dos íons $\mathrm{Cu}^{2+}$ e $\mathrm{Zn}^{2+}$, o mesmo não acontecendo com o $\mathrm{Pb}^{2+}$ e $\mathrm{Fe}^{2+}$. Com relação às análises cromatográficas de adsorção dos mesmos íon metálicos, utilizando-se quitosana em comparação com a quitina como fase estacionária, constatouse que, a quitosana, apresentou os melhores resultados quanto à recuperação dos íons $\mathrm{Zn}^{2+}$ e $\mathrm{Cu}^{2+}(95,6 \%$ para o cobre e $24,9 \%$ para o zinco) quando se usou a maior massa $(3,0 \mathrm{~g})$ e a menor granulometria $(<0,08 \mathrm{~mm})$. Diferente da quitina que recuperou melhor o íon $\mathrm{Fe}^{2+}(62 \%)$ em meio ácido do que os outros íons.

Palavras-chave: polissacarídeos, cromatografia, cátions.

Science and technology development has been influenced by natural vegetal biomass applications. Cellulose and Quitin are the most used macromolecule from natural vegetal biomass. When the polysaccharide, quitin, is chemically modified, it forms quitosan. The present work used Cellulose by itself and Cellulose impregnated with quitosan as stationary phase to separate metal cations, such as cooper, iron, lead and zinc. Chromatographic plates impregnated with quitosan improved ionic separation. Parallel to that, increasing quitosan concentration in cellulose layers increased $\mathrm{Cu}^{2+}$ and $\mathrm{Zn}^{2+}$ retention, but not $\mathrm{Fe}^{2+}$ and $\mathrm{Pb}^{2+}$. By comparing quitin and quitosan for adsorption of the same ion, the modified material presented better recoveries for $\mathrm{Cu}^{2+}$ and $\mathrm{Zn}^{2+}\left(95,6 \%\right.$ for $\mathrm{Cu}^{2+}$ and $24,9 \%$ for $\mathrm{Zn}^{2+}$ ) using mass of 3,0g and granulometry of 0,08 mm. Differently, using quitin in acid $\mathrm{pH}$ the best recovery between the investigated ions was $62,0 \%$ for $\mathrm{Fe}^{2+}$.

Keywords: polysaccharide, chromatographic, cations. 


\section{Introdução}

Vários estudos e pesquisas vêm sendo realizados visando o aproveitamento da biomassa vegetal e animal nas diversas áreas da ciência e tecnologia ${ }^{1-11}$. O componente macromolecular mais importante da biomassa vegetal é a celulose. Depois da celulose, a quitina é o polissacarídeo mais abundante presente na biomassa. O principal derivado de quitina é quitosana, produzido a partir da reação de desacetilação parcial de quitina, geralmente através de tratamento alcalino ${ }^{12-14}$, porém ela pode ocorrer naturalmente em alguns fungos ${ }^{15}$, mas é de ocorrência natural muito menos pronunciada que quitina.

Quitina e quitosana possuem características que tornam esses biopolímeros aptos para atuarem como materiais adsorventes tanto de cátions metálicos como de anions. Portanto, essas moléculas podem ser empregadas como suportes cromatográficos ${ }^{16-21}$.

Por serem bases de Lewis, essas moléculas podem se complexar com íons metálicos, mais ou menos eficientemente, em decorrência da natureza do metal, o que viabiliza a aplicação desses compostos como fase estacionária em processos cromatográficos para separação de cátions metálicos. Diante ao exposto, o objetivo deste trabalho foi investigar a aplicação de quitina e quitosana como fase estacionária em cromatografia de camada delgada e cromatografia de adsorção, na análise de íons cobre, zinco, ferro e chumbo.

\section{Parte experimental}

\section{CROMOTOGRAFIA DE CAMADA DELGADA}

Prepararam-se as placas de celulose Microcristalina Avicel $^{\circledR}$ adicionando $15 \mathrm{~g}$ desse tipo de celulose em 50 $\mathrm{mL}$ de água desionisada. No caso do preparo das placas de celulose Microcristalina Avicel ${ }^{\circledR}$ impregnada com quitosana, inicialmente dissolveu-se certa quantidade de quitosana em pó, a fim de se obter concentrações da solução de quitosana de 0,8, 1,5 e 2,0 (\%m/v), em $12 \mathrm{~mL}$ de ácido fórmico $2,5 \%(\mathrm{~m} / \mathrm{v})$, completando o volume para $60 \mathrm{~mL}$ com água desionizada. Finalmente a essas soluções recém preparadas de quitosana adicionou-se $15 \mathrm{~g}$ de celulose microcristalina Avicel ${ }^{\circledR}$ formando a fase estacionária da cromatografia de camada delgada.
Em placas de vidro $20 \mathrm{~cm}$ x $20 \mathrm{~cm}$ distribui-se as fases estacionárias com a espessura de 0,25 mm, e antes de serem usadas, as placas foram secas a temperatura ambiente, ativadas por 10 minutos a temperatura de 105 ${ }^{\circ} \mathrm{C}$. Aplicou-se os padrões de metais (cobre, chumbo, ferro e zinco) nas concentrações de $20 \mathrm{mg} . \mathrm{L}^{-1}$, sendo as análises realizadas em duplicatas. O eluente percorreu uma distância de $16 \mathrm{~cm}$, com o desenvolvimento dos cromatogramas em câmara de vidro, em saturação normal, à temperatura ambiente. Os eluentes utilizados foram solução tampão de $0,5 \mathrm{~mol} \cdot \mathrm{L}^{-1}$ nitrato de amônio / 0,5 mol. $L^{-1}$ de amônia, solução tampão de 0,5 mol.L $L^{-1}$ nitrato de amônio / 1,0 mol.L-1 de amônia e uma mistura de acetona/ água/ ácido clorídrico na proporção de 87:9:4. A detecção das manchas ocorreu por visualização, após aplicação dos reveladores de 8-hidroxiquinolina ou sulfeto de sódio em luz ultravioleta a $365 \mathrm{~nm}$. Para a leitura das placas utilizou-se a cromatografia unidimensional ascendente

\section{CROMATOGRAFIA DE ADSORÇÃO}

Para buretas de $25 \mathrm{~mL}$, que serviu de coluna cromatográfica, transferiu-se quantitativamente quitina ou quitosana previamente secas em estufa, e os eluentes (tampão de 0,5 mol.L-1 de nitrato de amônio / 0,5 mol.L $\mathrm{L}^{-1}$ de amônia ou ácido clorídrico $\mathrm{pH}$ 0,5). Após o preenchimento das colunas, adicionou-se $0,1 \mathrm{~mL}$ de cada padrão de metais (20 mg. $\mathrm{L}^{-1}$ de cobre, $20 \mathrm{mg}$. $\mathrm{L}^{-1}$ de chumbo, $20 \mathrm{mg}$. $\mathrm{L}^{-1}$ de ferro e $20 \mathrm{mg}^{-1} \mathrm{~L}^{-1}$ de zinco) e realizou-se a corrida do eluente em um fluxo de $1 \mathrm{~mL} \cdot \mathrm{min}^{-1}$. Retiraram-se oito frações de $20 \mathrm{~mL}$ cada, considerando as diferentes massas de quitosana (2,0; 2,5 e 3,0 g) e diferentes granulometrias $(<0,080$ e $\geq 0,100)$. Após as extrações, os metais eluídos, foram quantificados em duplicatas, por Espectrofotometria de Absorção Atômica com chama, usando um equipamento da CG modelo 2000. As leituras realizadas no equipamento foram avaliadas usando padrões de cobre, zinco, chumbo e ferro de concentração conhecidas.

\section{Resultados e discussão CROMATOGRAFIA EM CAMADA DELGADA}

Na separação dos íons metálicos, observou-se que ao se utilizar as soluções tampão como eluentes, conseguiuse separar o íon $\mathrm{Cu}^{2+}$ do $\mathrm{Zn}^{2+}$. Por outro lado, quando se 
empregou como fase móvel o sistema acetona/água/HCl eluiu-se os cátions $\mathrm{Cu}^{2+}$ e o $\mathrm{Pb}^{2+}$. Deve-se destacar que não se conseguiu a separação do ferro em nenhum dos casos testados. Pode se observar que há uma variação nos valores de retenção (Rf), os quais são fortemente dependentes do sistema de solvente empregado e da fase estacionária.

Foram testadas várias concentrações de metais $(1 \mathrm{mg} / \mathrm{L}$, 10mg/L, 20mg/L, $30 \mathrm{mg} / \mathrm{L}, 40 \mathrm{mg} / \mathrm{L}, 500 \mathrm{mg} / \mathrm{L}$ e 1000 $\mathrm{mg} / \mathrm{L}$ ) aplicadas na placa e os melhores resultados obtidos com relação ao tempo de retenção ocorreu quando se utilizou a concentração de $40 \mathrm{mg} . \mathrm{L}^{-1}$ e $500 \mathrm{mg} . \mathrm{L}^{-1}$. Com relação os eluentes, o tampão e a mistura acetona/água/HCl (87:9:4) apresentaram melhores resultados para o tempo de retenção. As concentrações menores que as citadas não apresentaram visualmente a eluição dos metais. Os resultados observados estão descritos a seguir (Tabela 1).

Tabela 1. Valores médios de fator de retenção (Rf) obtidos na análise cromatográfica por camada delgada dos íons metálicos.

\begin{tabular}{|c|c|c|c|}
\hline \multirow{2}{*}{$\begin{array}{c}\text { Fase } \\
\text { Estacionária }\end{array}$} & $\mathbf{R f}$ & $\mathbf{R f}$ & $\mathbf{R f}$ \\
\hline & (Eluente 1) $^{\mathrm{a}}$ & (Eluente 2) $^{\mathbf{b}}$ & (Eluente 3) $^{c}$ \\
\hline \multirow{4}{*}{ Celulose } & Cu: N/E & Cu: $0,77 \pm 0,01$ & - \\
\hline & Pb: N/E & Pb: $0,84 \pm 0,02$ & - \\
\hline & Fe: N/E & Fe: N/E & - \\
\hline & Zn: $0,95 \pm 0,01$ & Zn: N/E & - \\
\hline \multirow{4}{*}{$\begin{array}{c}\text { Celulose } \\
\text { impregnada } \\
\text { com solução } \\
\text { 0,8\% de } \\
\text { quitosana }\end{array}$} & Cu: $0,81 \pm 0,01$ & Cu: $0,68 \pm 0,01$ & $0,74 \pm 0,02$ \\
\hline & $\mathrm{Pb}: \mathrm{N} / \mathrm{E}$ & $\mathrm{Pb}: 0,62 \pm 0,02$ & $\mathrm{~N} / \mathrm{E}$ \\
\hline & Fe: N/E & Fe: N/E & N/E \\
\hline & Zn: $0,92 \pm 0,01$ & Zn: N/E & $0,87 \pm 0,02$ \\
\hline \multirow{4}{*}{$\begin{array}{c}\text { Celulose } \\
\text { impregnada } \\
\text { com solução } \\
\text { 1,5\% de } \\
\text { quitosana }\end{array}$} & Cu: $0,64 \pm 0,02$ & Cu: $0,52 \pm 0,02$ & - \\
\hline & $\mathrm{Pb}: \mathrm{N} / \mathrm{E}$ & $\begin{array}{c}\text { Pb: } 0,35 \pm \\
0,02 *\end{array}$ & - \\
\hline & Fe: N/E & Fe: N/E & - \\
\hline & Zn: $0,86 \pm 0,01$ & Zn: N/E & - \\
\hline \multirow{4}{*}{$\begin{array}{c}\text { Celulose } \\
\text { impregnada } \\
\text { com solução } \\
\text { 2,0\% de } \\
\text { quitosana }\end{array}$} & Cu: $0,48 \pm 0,03$ & Cu: $0,63 \pm 0,01$ & - \\
\hline & $\mathrm{Pb}: \mathrm{N} / \mathrm{E}$ & $\mathrm{Pb}: 0,28 \pm 0,01$ & - \\
\hline & Fe: N/E & Fe: N/E & - \\
\hline & Zn: $0,81 \pm 0.03$ & Zn: N/E & - \\
\hline
\end{tabular}

(a) Tampão (0,5 mol.L-1 de NH4NO3 / 0,5 mol.L-1 de amônia), concentração do metal $=40 \mathrm{mg} / \mathrm{L}$; (b) Eluente: acetona/ água/ ácido clorídrico, concentração do metal = 500mg/L; (c) Tampão 0,5 mol.L-1 de NH4NO3/ 1,0 mol.L-1 de amônia, concentração do metal = 40mg/L. Obs.: N/E = não eluiu
Quando se utilizou apenas celulose como fase estacionária somente o zinco foi separado. As placas cromatográficas impregnadas com quitosana, independentemente da concentração, eluíram tanto o cobre como o zinco. Por outro lado, em nenhuma situação o ferro e chumbo migraram, o que sugere que o sistema formado pelo tampão como eluente e ambas as fases estacionárias não são adequados para a separação destes metais.

Observou-se que o aumento da concentração de quitosana produz uma melhor separação dos metais cobre e zinco, apesar de que este aumento diminui os valores do fator de retenção (Rf) do $\mathrm{Cu}^{2+}$ e $\mathrm{Zn}^{2+}$. Como o valor do fator de retenção (Rf) foi mais pronunciado para o cobre, isto sugere que esse metal apresenta mais afinidade com a quitosana que o zinco, no eluente estudado.

As separações de $\mathrm{Cu}^{2+}$ e $\mathrm{Pb}^{2+}$ tanto quando se utilizou as fases estacionárias de celulose pura ou celulose impregnada com quitosana, na presença do eluente acetona/ água/ ácido clorídrico foram melhores observadas. No entanto nos dois outros íons $\mathrm{Fe}^{3+} \mathrm{e} \mathrm{Zn}^{2+}$, não houve eluição, sugerindo que os sistemas utilizados não são adequados para a separação destes metais, porque os valores de fator de retenção diminuíram, ou seja, os metais ficam mais retidos na placa. Visualmente percebeu-se também que, com o aumento da concentração de quitosana impregnada, cresce o efeito “cauda” para o metal chumbo.

Ao se comparar os tampões com diferentes concentrações $\left(0,5\right.$ mol. $\mathrm{L}^{-1}$ de nitrato de amônio / 1 mol. $\mathrm{L}^{-1}$ de amônia e $0,5 \mathrm{~mol} . \mathrm{L}^{-1}$ de nitrato de amônio / 0,5 mol. $\mathrm{L}^{-1}$ de amônia), para verificar a influência da força iônica nos valores de fator de retenção, observouse que ao diminuir a força iônica, os valores de $\mathrm{Rf}$ aumentaram, ou seja, quanto maior a força iônica mais retidos ficam os metais.

\section{CROMATOGRAFIA DE ADSORÇÃO}

Os resultados das extrações dos metais utilizando quitina ou quitosana como fase estacionária, estão mostrados a seguir (Tabela 2). Quando se utilizou a quitosana como fase estacionária se observou que os íons cobre e zinco foram extraídos, ao contrário do que foi verificado para os íons ferro e chumbo. Deve-se destacar que esses resultados já eram esperados, pois vão de encontro 
às observações dos estudos realizados dos tempos de retenção em Cromatografia em Camada Delgada realizados anteriormente. Nota-se, também que houve uma maior recuperação de $\mathrm{Cu}^{2+}$ do que $\mathrm{Zn}^{2+}$, porém o cobre, independentemente da situação, ficou mais retido na coluna (Figura 1). Esse resultado pode ser explicado por uma diminuição da adsorção da fase móvel e aumento na adsorção relativa do cátion $\mathrm{Cu}^{2+}$, o que diminui a velocidade de eluição do íon.

Com diminuição na granolumetria da quitosana foi observado que a quantidade do metal extraído aumentou, porém o cobre ficou mais retido na coluna (Figuras 1a e 1c). Estas mudanças são devidas ao aumento da área superficial de contato da fase estacionária (quitosana) com o metal, modificando o grau de interação entre as espécies envolvidas.

Com aumento da massa de quitosana no enchimento da coluna (Tabela 2) observa-se um aumento na quantidade do metal recuperado, além do que, tanto o cobre como o zinco ficam mais retidos na coluna (Figuras 1b, 1b e 1c). O aumento da massa aumenta interação do metal com a quitosana, diminuindo a velocidade de eluição e por conseqüência necessitando de um maior volume de fase móvel para a extração.

Diferentemente da quitosana, a quitina pode ser usada como suporte cromatográfico com eluentes ácidos, pois esta não é solúvel nessa situação. Assim, uma solução de ácido clorídrico, além uma solução tampão 0,50 mol.L-1 de $\mathrm{NH}_{4} \mathrm{NO}_{3} /$ 0,50 mol.L-1 de amônia, foram usados como eluentes nas análises cromatográficas. Os dois eluentes apresentaram separação dos metais cobre e zinco, porém, nas condições ácidas tem-se também a extração do ferro. Entretanto, o chumbo novamente não foi separado com os eluentes estudados.

Ao contrário do que foi observada com a quitosana, a solução tampão como fase móvel, mostrou-se ineficiente, pois apesar de separar os íons $\mathrm{Zn}^{2+}$ e $\mathrm{Cu}^{2+}$, não promove uma boa recuperação desses cátions, apresentando porcentagem de extração igual a 4,9\% e 7,0\%, respectivamente. Este comportamento diferente entre quitosana e quitina era esperado, pois a predominância do grupo amino na quitosana modifica bastante o caráter do polímero. A retenção desses dois metais no suporte cromatográfico contendo quitina mostrou-se muito semelhante no eluente tampão (Figura 2a).
Tabela 2. Resultados da extração dos metais utilizando quitosana como fase estacionária.

\begin{tabular}{|c|c|c|c|c|}
\hline Polimero & $\begin{array}{c}\text { Granolumetria } \\
(\mathrm{mm})\end{array}$ & $\begin{array}{c}\text { Massa } \\
\text { (g) }\end{array}$ & $\begin{array}{c}\text { Metal } \\
\text { Extraído } \\
(\%)\end{array}$ & $\begin{array}{c}\text { Volume } \\
\text { Eluido } \\
\text { (mL) }\end{array}$ \\
\hline \multirow{12}{*}{ Quitosana( $\left.{ }^{\mathrm{a}}\right)$} & \multirow{12}{*}{$<0,080$} & \multirow{4}{*}{2,0} & Cu: 42,5 & 80 \\
\hline & & & Pb: 0,0 & --- \\
\hline & & & Fe:0,0 & --- \\
\hline & & & Zn :11,8 & 60 \\
\hline & & \multirow{4}{*}{2,5} & Cu: 68,0 & 100 \\
\hline & & & Pb: 0,0 & --- \\
\hline & & & Fe:0,0 & --- \\
\hline & & & Zn :20,0 & 60 \\
\hline & & \multirow{4}{*}{3,0} & Cu: 95,6 & 120 \\
\hline & & & Pb: 0,0 & --- \\
\hline & & & $\mathrm{Fe}: 0,0$ & --- \\
\hline & & & Zn: 24,9 & 80 \\
\hline \multirow{4}{*}{ Quitosana $\left({ }^{a}\right)$} & \multirow{4}{*}{$\geq 0,100$} & \multirow{4}{*}{2,5} & Cu: 62,3; & 80 \\
\hline & & & Pb: 0,0 & --- \\
\hline & & & Fe: $0 ; 0$ & --- \\
\hline & & & $\mathrm{Zn}: 8,3$ & 60 \\
\hline \multirow{4}{*}{ Quitina( $\left.{ }^{a}\right)$} & \multirow{4}{*}{$\geq 0,100$} & \multirow{4}{*}{2,5} & $\mathrm{Cu}: 4,9$ & 60 \\
\hline & & & Pb: 0,0 & --- \\
\hline & & & Fe: 0,0 & -- \\
\hline & & & $\mathrm{Zn}: 7,0$ & 60 \\
\hline \multirow{4}{*}{ Quitina( $\left(^{b}\right)$} & \multirow{4}{*}{$\geq 0,100$} & \multirow{4}{*}{2,5} & Cu: 23,7 & 40 \\
\hline & & & Pb: 00,0 & -- \\
\hline & & & Fe: 62,0 & --- \\
\hline & & & Zn: 56,2 & 40 \\
\hline
\end{tabular}

(a) Eluente: Tampão 0,50 mol.L-1de NH4NO3 / 0,50 mol.L-1 de amônia; (b) Ácido Clorídrico, pH 0,5

\section{Conclusão}

Os resultados obtidos nesse trabalho permitem concluir:

a) A fase estacionária resultante da adição de quitosana a celulose é eficiente na separação de íons $\mathrm{Cu}^{2+}$ e $\mathrm{Zn}^{2+}$, quando se utiliza uma solução tampão como fase móvel;

b) A maior concentração de quitosana impregnada às camadas de celulose aumenta a retenção dos íons $\mathrm{Cu}^{2+}$ e $\mathrm{Zn}^{2+}$, além de melhorar a resolução da análise;

c) A fase estacionária impregnada com quitosana leva a maior retenção dos íons metálicos, ao empregar-se a mistura acetona/água/ $\mathrm{HCl}$ como fase móvel; 

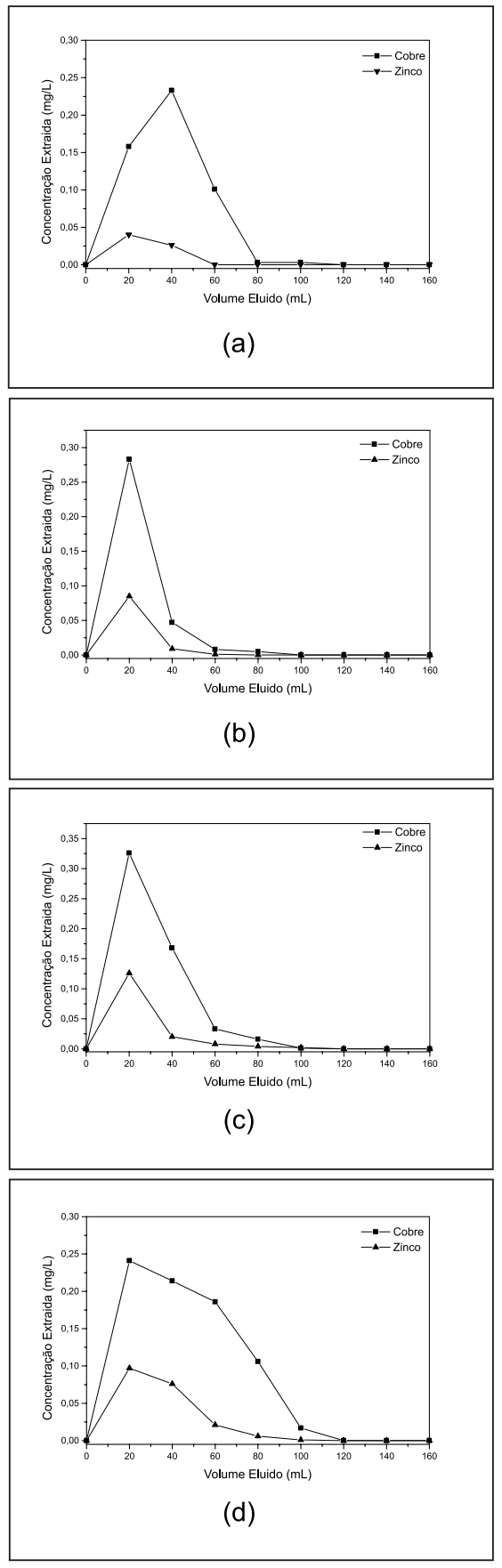

Figura 1. Extração dos metais cobre e zinco utilizando quitosana como fase estacionária e o eluente Tampão 0,50 mol.L-1 de NH4NO3 / 0,50 mol. $\mathrm{L}^{-1}$ de amônia. (a) massa da quitosana de 2,5 g e tamanho granular $\geq 0,100 \mathrm{~mm}$; (b) massa da quitosana de $2,0 \mathrm{~g}$ e tamanho granular $<0,080$ $\mathrm{mm}$; (c) massa da quitosana de 2,5 g e tamanho granular $<0,080 \mathrm{~mm}$; (d) massa de quitosana de 3,0 g e tamanho granular $<0,080 \mathrm{~mm}$.

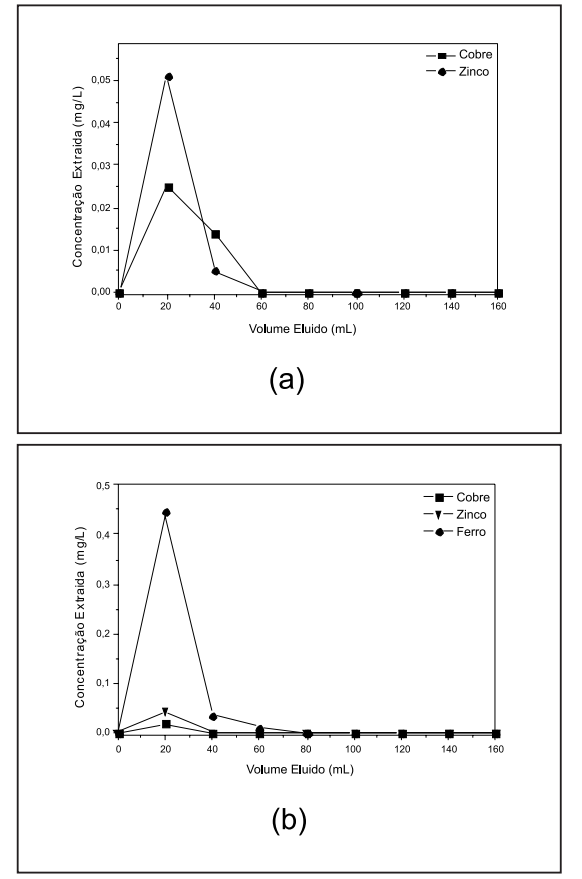

Figura 2. Extração dos metais cobre, zinco e ferro utilizando quitina como fase estacionária eluente. (a) Eluente: Tampão 0,50 mol.L-1 de $\mathrm{NH}_{4} \mathrm{NO}_{3} /$ 0,50 mol.L-1 de amônia (b) Eluente: ácido clorídrico, $\mathrm{pH}$ 0,5

d) $\mathrm{O}$ íon $\mathrm{Cu}^{2+}$ apresenta boa afinidade por quitosana, possuindo o maior fator de retenção (Rf), quando se emprega como fase móvel a mistura acetona/água/ $\mathrm{HCl}$;

e) O eluente tampão utilizado na cromatografia de adsorção com quitosana como suporte cromatográfico, é adequado para a separação dos íons $\mathrm{Cu}^{2+}$ e $\mathrm{Zn}^{2+}$, porém essa fase móvel é mais eficiente na recuperação do cobre;

f) O ferro e o chumbo não eluíram em nenhuma condição em que foi utilizada quitosana;

g) Ao utilizar quitina como fase estacionária o ferro foi separado, indicando que a força iônica, o tamanho granular e a massa da fase estacionária influenciam na análise cromatográfica, devido à mudança no processo de adsorção.

A utilização da análise cromatográfica em Camada Delgada e de Adsorção, são metodologias úteis para a detecção ou eluição do metais: cobre, zinco, chumbo e 
ferro, quando se utiliza a quitosana e a quitina como fases estacionárias, mas ambas as fases dependem do eluente e da fase móvel utilizada.

\section{Agradecimentos}

O presente trabalho foi realizado com o apoio do CNPq, uma entidade do Governo Brasileiro voltada ao desenvolvimento científico e tecnológico.

\section{Referências}

1. Shahidi,F.; Arachchi, J.K.V.; Jeon Y-J.; Trends Food Sci. Technol. 1999,10, 37.

2. Roller, S.; Covill, N.; Int. J. Food Microbiology, 1999, 47, 67.

3. Kurita, K.; Polym. Degrad. and Stab. 1998, 59,117.

4. Li, Q.; Dunn, E. T.; Grandmaison, M. F. A.; Goose, M.F.A.; J. Bio. Comp. Polym., 1992, 7, 370.

5. Kumar, M. N. V. R., Reactive \& Functional Polymers 2000, 46, 1.

6. Felt, O.; Buri, P.; Gurny, R.: Drug Dev. Ind. Pharm. 1998, 24, 979.

7. Prashanth,K. V. H.; Tharanathan, R. N.; Trends Food Sci. Technol. 2007, 18, 117.

8. Kanatt, S. R.; Chander, R.; Sharma, A.; Food Chem. 2008, 106,521

9. Wu, J.: Wei, W.; Wang, L-Y.; Su, Z-G.; Ma, G-H.; Biomaterials 2007, 28, 2220.

10. Boucard, N.; Viton, C.; Agay, D.; Mari, E.; Roger, T.; Chancerelle, Y.; Domard, A. Biomaterials 2007, 28, 3478.

11. Madhavan, P.; Nair, K.G.; Fishery Technology, 1974, 11, 50.

12. Horton, D.; Lineback, D.R.; Methods Carbohydrate Chemistry, 1965, 5, 403.
13. Chang, K.L.B.; Tsai, G.; Lee, J.; Fu, W.; Carbohydr. Res., 1997, 303, 327.

14. Muzzarelli, R.A.A. Em Chitin; Mark, H.F.; Bikales, N.M.; Overberger, C.G.; Menges, G., eds.; 2.ed.; John Wiley \& Sons: Nova Jersey, 1985, v.3.

15. Thome, J.P.; Weltrowski, M.; Em Advances in Chitin Science, Domard, A.; Roberts, G.A.F. ; Varum, K.M. (eds), 2002, v.2.

16. Silva, K.M.P., Bravo, R. V. F. Anais da Associação Brasileira de Química, 1999, 48(1),16.

17. Muzzarelli, R.A.; Rochetti, R. Anal. Chim. Acta. 1973, 64, 371.

18. Muzzarelli, R.A.A.; Raith, G., Tubertini, O. J. Chromatogr. 1970, 47, 414.

19. Lepri, L.; Desideri, P.G.; Muzzarelli, R.A.A. J. Chromatogr. 1977, 139, 337.

20. Nagasawa, K.; Watanabe, H.; Ogamo, A. J. Chromatogr. 1971, 56, 378.

21. Lepri, L.; Desideri, P.G.; Tanturli, G. J. Chromatogr. 1978, 147, 375.

\section{Roberta Signini, ${ }^{*}$ Ellen C. G. Moura, ${ }^{2}$ Maria G. O. Tavares ${ }^{2} \&$ Guilherme R. Oliveira².}

${ }^{1}$ Faculdade de Tecnologia SENAI Roberto Mange, Av. Eng. Roberto Mange, 239, Jundiaí, Anápolis - GO, CEP 75.113-630

${ }^{2}$ Universidade Federal de Goiás, Caixa Postal 131, Goiânia - GO, CEP 74001-970.

*e-mail: rsignini@terra.com.br 